\title{
Pelvic floor muscle training program for Egyptian women with neglected urinary incontinence
}

\author{
Mona Amin Hassan Hussein , Hanan El-Sayed Mohamed, Amina Mohamed Rashad El-Nemer \\ Faculty of Nursing, Mansoura University, Mansoura, Egypt
}

Received: December 27, 2014

Accepted: January 30, 2015

Online Published: March 13, 2015

DOI: $10.5430 /$ jnep.v5n5p92

URL: http://dx.doi.org/10.5430/jnep.v5n5p92

\begin{abstract}
Urinary incontinence (UI) is an extremely common complaint in every part of the world. It causes a great deal of distress and embarrassment, as well as significant costs, to both individuals and societies. The aim of this study was to evaluate the effect of pelvic floor muscle training (PFMT) program on women complaining of urinary incontinence. Quasi experimental design was utilized. The study was conducted in Talkha Maternal and Child Health (MCH) Center, Dakahlia governorate from May 2013 to April 2014. The study subjects included 140 women visiting Talkha MCH Center. Three tools were used for data collection. Woman's health assessment sheet was developed by the researcher, the second tool was quality of life as measured by incontinence impact questionnaire, and the third tool was the follow up sheet. Study results showed a statistically significant positive effect of PFMT on UI and the women's quality of life. The study recommended providing a guideline to develop clinical teaching and in- service education programs for all maternity nurses and nursing educators regarding the UI and PFMT as a preventive as well as treatment modality for UI. Furthermore, community awareness about the positive effect of practicing PFME among incontinent women is recommended.
\end{abstract}

Key Words: Urinary incontinence, Women, Pelvic floor muscle, Training, Sandvik incontinence Severity index, Quality of life

\section{INTRODUCTION}

Urinary incontinence (UI) is an extremely common complaint affecting approximately 250 million adults in the world population. ${ }^{[1,2]} \mathrm{UI}$ affects up to $37 \%$ of adult women of all ages, although the prevalence increases with age. UI is commonly associated with pregnancy and childbirth, however, it is not restricted to women who have borne children - in fact, $12 \%$ of women who have never had children and are aged under 30 have incontinence. ${ }^{[3]}$

The International Continence Society (ICS) defined incontinence as "the complaint of any involuntary leakage of urine that is a social or hygienic problem and is objectively demonstrable". ${ }^{[4]}$ UI encompasses three basic types: transient (acute), neurogenic, and established (persistent). Transient incontinence is usually associated with an acute medical or surgical condition. ${ }^{[5]}$ Neurogenic incontinence, and neurogenic bladder dysfunction, may have a sudden or progressive onset, depending on the disease or trauma that causes the lesion within the nervous system. UI other than transient or neurogenic is considered as established or persistent incontinence. Based on etiology and pathophysiology, the most commonly encountered clinical forms of established UI in the adults are stress UI (SUI), urge UI (UUI), and mixed UI (MUI). ${ }^{[6]}$

SUI is the most common type of incontinence, especially in middle aged-women. SUI is defined as the involuntary

\footnotetext{
*Correspondence: Mona Amin Hassan Hussein; Email: monaameen550@ hotmail.com; Address: Faculty of Nursing, Mansoura University, Mansoura, Egypt.
} 
leakage of urine with exertion such as coughing, sneezing, and laughing. ${ }^{[7]}$ UUI is defined as the involuntary leakage of urine accompanied by or immediately preceded by a strong sudden urge to urinate. ${ }^{[8]}$ MUI is the involuntary leakage of urine associated with exertion and urgency. It is a mixture of Stress and UUI. ${ }^{[9]}$

Lots of factors make women at risk for UI. The female urethra is very short allowing easy damage to the urethral sphincter mechanism. During Pregnancy, pressure of gravid uterus and relaxing effect of hormones on urinary sphincters increases risk of UI by 33\%. Childbirth can cause damage to urethral supports and sphincters. Menopausal loss of estrogen results in weaker collagen which adversely affects the urethral supports and urinary sphincters. All these factors make the ratio of occurrence between female to male to be three to one. ${ }^{[10]}$

According to El-Azab and Shaaban, the prevalence of UI among Egyptian women is 54\%. The number, however, may actually be higher because most Egyptian women are reluctant to seek help regarding this problem and thus more studies are required to estimate the exact magnitude of the problem. Women often do not report incontinence nor are they routinely asked about incontinence when they visit their health care providers. It appears that a combination of embarrassment and the belief that UI is a natural consequence of ageing and childbirth discourages women from seeking appropriate treatments. ${ }^{[11]}$

Urine leakage occurs when the pressure in the bladder is greater than the pressure within the urethra, i.e. the expulsive force overcomes the closure force. At this point involuntary loss of urine occurs. When there is a weakness in the pelvic floor muscles (PFM) that support the bladder and other pelvic organs, these organs could prolapse and cause additional pressure on the bladder, leading to leakage of urine. ${ }^{[12,13]}$ PFME are designed to strengthen weak perineal and PFM. ${ }^{[14]}$

Urinary incontinence is not a life threatening condition, though it has a strong, if not devastating, impact on quality of life (QOL) of the patients. Women with incontinence may suffer from social isolation, loneliness, sadness, depression, embarrassment, stigmatization and disturbed sleep. Moreover sexual relationships and marital satisfaction are greatly affected. ${ }^{[15,16]}$ Women with UI have a fear to be exposed to environments where access to a bathroom may be difficult which restrict their social activities. ${ }^{[17]}$ The need to bathe, change clothing, and bed linen are often frequent. ${ }^{[18]}$ This necessitates planning ahead for determining possible solutions to the problem.

Nurses must be more creative, inventive, and bold in devel- oping new approaches to prevent and manage UI. ${ }^{[18]}$ Furthermore, nurses have a vital role to play in the promotion of continence. This role extends across the dimensions of researchbased practice, education, training, development and implementation of high quality practices. In addition, one of the prevalent roles of nurses is teaching women to maintain optimal health, to prevent complications, and to help women in the restoration of normal functions. ${ }^{[19]}$ Accordingly, nurses are important resources to incontinent women in assisting with the selection and management of techniques. They are coordinators of care, communicating with family, and members of the health care team. Moreover, nurses may be the most cost- effective health care provider to deal with UI. ${ }^{[20]}$

Various interventions are available for preventing and treating incontinence, including medication, medical devices and surgery. ${ }^{[21-26]}$ Pelvic floor muscle exercise (PFME) may be the easiest to implement since it needs no special equipment or other costly resources and it is commonly recommended for both prevention and treatment of incontinence. ${ }^{[27]}$

It would be appropriate to test the effect of PFME program which is one of the suggested solutions to UI under the conditions that are prevalent in Egypt such as multi parity, early marriage, less spacing between the pregnancies, low menopausal awareness, and poor perineal hygiene. Thus, this study attempts to evaluate effectiveness of PFMT program on women with UI.

\subsection{Aim of the study}

The aim of the study is to evaluate the effectiveness of PFME program on Egyptian women complaining of UI.

\subsection{Hypothesis}

(1) PFMT program has a positive effect as a treatment of female UI.

(2) PFMT program has a positive effect on Quality of Life.

\section{SUBJECTS AND METHODS}

\subsection{Study design}

The study was utilized using a Quasi Experimental design with intervention and control groups.

\subsection{Study setting}

This study was conducted in Talkha MCH Center, Ministry of Health (MOH), Dakahlia Governorate, where women come for antenatal care, family planning, and immunization during the period from May 2013 to April 2014. 


\subsection{Study subjects}

The subjects of the study included 140 women visiting Talkha $\mathrm{MCH}$ Center. A written informed consent was obtained from all participants. Eligible women were randomly allocated into two groups by means of block randomization (block size of 4) using the concealed envelope method:

- Group I: The intervention group consisted of 70 women who enrolled in the PFMT program.

- Group II: The control group consisted of 70 women. This group received the usual care in MCH center only, and was assessed monthly without intervention.

\subsection{Inclusion criteria}

- Women aged 20 years and up to the end of childbearing period

- Have stress UI, urge UI, or mixed UI with at least one episode of involuntary loss per month

- Healthy women with no previous or current UI treatment

\subsection{Exclusion criteria}

Women were excluded if they have UI as their chief complaint.

\subsection{Tools of data collection}

- Tool I. Woman's Health Assessment Sheet

- Tool II. Incontinence impact questionnaire - short form (IIQ-7)

- Tool III. Follow Up Assessment

\section{Tool I: Woman's health assessment sheet}

This questionnaire was developed and completed by the researcher at the first interview with the woman. It consists of three parts:

Part One: This part was developed to collect data about socio-demographic characteristics which include name, age, education, marital condition, occupation, residence, income and telephone number, medical and surgical history, family history, obstetrical history such as gravidity, parity, mode of delivery in previous pregnancy.

Part Two: This part is concerned with data regarding characteristics of UI such as onset, frequency, duration, precipitating circumstances, the amount of leakage and type of incontinence (urge, mixed, or stress incontinence).

Part Three: This part includes the outcome measures and the body mass index (BMI).

1) Sandvik Incontinence Severity Index (ISI): The Sandvik Incontinence Severity Index (ISI) is the primary outcome measure in the current study. The Sandvik ISI is well validated, and is calculated by multiplying the reported frequency of UI (less than 1 time a month, 1-3 times a month, 1 time a week, 1 time a day) by the amount of leakage (drop, more than drop). Frequency of UI is assigned a value from 1 to 4 , with a higher number indicating greater frequency, and amount of leakage is assigned a value of 1 for one drop or 2 for more than a drop. ${ }^{[28]}$

2) Vaginal digital test: This test involved inserting a gloved and lubricated finger into the woman's vagina and asking her to squeeze around the examiner's finger to assess her ability to contract the muscle. PFM tone is identified according to the following scale: 0 for "no contraction", 1 for "poor contraction (slight pressure)", 2 for "good contraction (medium hard pressure for less than 5 seconds)" and 3 for "strong contraction (powerful pressure for more than 5 seconds". [29]

3) Provocation test: This test evaluates the amount of leakage during and after the woman coughing vigorously for 5 times. ${ }^{[30]}$ Urine leakage is identified according to the following scale: 0 for "no leakage", 1 for "slight leakage (a few drops of urine)", 2 for moderate leakage during approximately first half of the test and 3 for "severe leakage during the whole test".

\section{Tool II: Incontinence impact questionnaire - short form} (IIQ-7)

The incontinence impact questionnaire (IIQ) -7 was originally used to evaluate the impact of UI on health -related quality of life (QOL). ${ }^{[31,32]}$ In our study, the IIQ-7 is considered as a secondary outcome measure. The questionnaire includes seven items; women were asked to what extent urine leakage affected physical activity, household chores, social activities, entertainment, travel, emotional health, and the extent to which they were frustrated by urine leakage. Response options were "greatly", "moderately", "slightly" or "not at all". Reponses were assigned values of 0 for "not at all", 1 for "slightly", 2 for "moderately" and 3 for "greatly". The total score is the sum of questions 1-7. The average score of items was calculated and this average was then multiplied by $331 / 3$ to convert scores to a scale of 0 to 100 . The higher the total score of the IIQ-7, the greater the negative impact on health- related QOL.

\section{Tool III: Follow up assessment}

It included questions to measure the output and outcome of the program as:

- Compliance with the PFMT measured by the 7- days exercise diary, which is completed by the woman and assesses the adherence in terms of number of days per week a woman had followed the researcher's advice in performing the program. 
- Progress of UI was measured by reassessing the characteristics of UI using part two of tool I, and by performing physical examinations at the end of the program using part two of tool I.

- Change in QOL was assessed by using the QOL assessment sheet (tool II) monthly and at the end of the program.

\subsection{Field of work}

\section{Baseline assessment}

Women were personally asked about the presence of UI. Accordingly an interview was conducted by the researcher. At baseline, data about socio-demographic characteristics, obstetrical history and characteristics of urinary incontinence were collected using the woman's health assessment sheet. Physical examination including the vaginal digital test, the provocation test and body mass index were also performed. Data regarding the quality of life were collected using the IIQ- 7.

\subsection{Intervention}

- Explanation of the nature and the aim of the study were discussed with all women included in the study. itemitem According to the study criteria, the selected women were assigned into intervention and control group. Matching between the two groups was fulfilled according to severity of the cases and the known risk factors such as age, pregnancy and BMI.

- Sufficient number of controls was selected to deal with any drop e.g. give chance for any case to join the PFMT program if they wish and if they go for any other medical intervention.

- Health education session for the intervention group about the PFME program in thirty minutes for each woman was conducted. The session covered introduction to the program, back ground information, explaining the procedure and answering the women's inquiries.

- Each woman in the intervention group was taught to perform exercises according to the Take Home Educational Material (THEM) which was prepared based on the literature review. They were asked to repeat the exercise to ascertain that they have understood the proper way of performing it. The researcher had aimed to achieve minimum exercise compliance of 4 sessions per day. All the exercises were taught by the researcher herself. Confidentiality of each individual session was maintained. At the end of each educational session, the THEM and exercise diary were handed to the woman. - The program supervision and follow up of women was implemented by weekly telephone communication. Monthly meetings with the participating women were held for follow up, and refreshing information. The women were requested to come for follow up after 4 weeks, 8 weeks and 12 weeks when they come to the health centre for family planning and consultation purpose.

- During the follow up, simple Vaginal Digital Examination, Provocation Test, Sandvik ISI, BMI, characteristics of UI and QOL were assessed to evaluate changes in the PFM strength and degree of incontinence and QOL. The compliance to the exercise schedule was ascertained by follow ups and checking the exercise dairy. Also, the women were asked to show how they were performing the exercises.

- The control group was also reassessed on a monthly basis and at the end of the study.

\section{RESULTS}

As shown in Table 1, a total of 140 women with UI were enrolled in this study. Women were randomized into two groups (a) the intervention group; and (b) the control group. The baseline characteristics of the two groups were similar as regards to age, BMI, educational status, occupational status, presence of family history of incontinence, smoking, obstetric history and gynecologic history.

\subsection{Effect of PFME on the Sandvik ISI}

As shown in Table 2, the Sandvik ISI at baseline was similar in the two groups; however, after 3 months the Sandvik ISI of the intervention group was significantly lower than the control group $(2.04 \pm 1.8 \& 5.09 \pm 1.7$ respectively). This difference was significant $(95 \% \mathrm{CI},-3.63 ;-2.45, p<.001)$. The PFME has reduced the Sandvik ISI from $5.7 \pm 1.7$ to $2.04 \pm 1.8$ in the intervention group $(p<.001)$

Figure 1 demonstrates the change in the Sandvik ISI over the 3-month treatment period in the intervention and control groups. One-month intervention yielded a reduction of the average Sandvik ISI from $5.7 \pm 1.7$ to $4.3 \pm 1.4$ then a further reduction to $3 \pm 1.3$ was obtained at the end of two-month intervention. By the end of the 3-month treatment the Sandvik ISI was 2.04 \pm 1.8 . Repeated measure ANOVA test showed that these changes were statistically significant $(p<.001)$.

Figure 2 demonstrates the complete cure rate and improvement rate after 3 months in the intervention group. After 3 months, $24(34.3 \%)$ women in the intervention group had complete cure (score 0 in the Sandvik ISI) and 46 (65.7\%) of the patients had improved. 
Table 1. Some Socio-demographic characteristic of study group

\begin{tabular}{|c|c|c|c|c|c|c|}
\hline & \multicolumn{2}{|c|}{ Intervention group } & \multicolumn{2}{|c|}{ Control group } & \multicolumn{2}{|c|}{ Chi square test } \\
\hline & $\mathbf{n}$ & $\%$ & $\mathbf{n}$ & $\%$ & $\chi^{2}$ & $p$ \\
\hline Age (years) (mean \pm SD) & $34.1 \pm 6.9$ & & $34.3 \pm 7$ & & $0.183^{*}$ & .855 \\
\hline $\mathrm{BMI}\left(\mathrm{kg} / \mathrm{m}^{2}\right)($ mean $\pm \mathrm{SD})$ & $30 \pm 5.2$ & & $29.2 \pm 4.5$ & & $0.918^{*}$ & .360 \\
\hline \multicolumn{7}{|l|}{ Educational status (n, \%) } \\
\hline Illiterate & 10 & $13.9 \%$ & 13 & $18.6 \%$ & $1.996^{*}$ & \multirow{5}{*}{.736} \\
\hline Read-write & 13 & $18.1 \%$ & 12 & $17.1 \%$ & & \\
\hline Primary school & 0 & $0 \%$ & 1 & $1.4 \%$ & & \\
\hline Secondary school & 39 & $54.2 \%$ & 34 & $48.6 \%$ & & \\
\hline University & 8 & $11.4 \%$ & 10 & $14.3 \%$ & & \\
\hline \multicolumn{7}{|l|}{ Employment status (n, \%) } \\
\hline Housewife & 50 & $69.4 \%$ & 43 & $61.4 \%$ & \multirow[t]{2}{*}{$1.569 *$} & \multirow[t]{2}{*}{.210} \\
\hline Work & 20 & $27.8 \%$ & 27 & $38.6 \%$ & & \\
\hline Family history of incontinence & 34 & $48.6 \%$ & 36 & $51.4 \%$ & $0.114^{*}$ & .537 \\
\hline Smoking & 0 & $0 \%$ & 2 & $2.9 \%$ & \multirow{4}{*}{$2.550^{*}$} & \multirow{4}{*}{.279} \\
\hline Never & 31 & $43.1 \%$ & 36 & $37.1 \%$ & & \\
\hline Passive & 39 & $54.2 \%$ & 42 & $60 \%$ & & \\
\hline Smoking & 0 & $0 \%$ & 2 & $2.9 \%$ & & \\
\hline History of gynecological surgery & 2 & $2.8 \%$ & 0 & $0 \%$ & $2.029 *$ & .363 \\
\hline \multicolumn{7}{|l|}{ Obstetric history (mean \pm SD) } \\
\hline Gravidity & \multicolumn{2}{|l|}{$2.5 \pm 1.3$} & \multicolumn{2}{|l|}{$2.8 \pm 1.3$} & $1.331^{*}$ & \multirow{2}{*}{$\begin{array}{l}.185 \\
.738\end{array}$} \\
\hline Abortion & \multicolumn{2}{|l|}{$0.2 \pm 0.5$} & \multicolumn{2}{|l|}{$0.17 \pm 0.5$} & $0.335^{*}$ & \\
\hline Parity & \multicolumn{2}{|l|}{$3 \pm 1.2$} & \multicolumn{2}{|l|}{$2.8 \pm 1.1$} & $1.241^{*}$ & .217 \\
\hline \multicolumn{7}{|l|}{ Mode of delivery } \\
\hline Normal labor & 25 & $34.7 \%$ & 32 & $45.7 \%$ & \multirow{4}{*}{$5.717 *$} & \multirow{4}{*}{.126} \\
\hline Normal labor with episiotomy & 35 & $48.6 \%$ & 25 & $35.7 \%$ & & \\
\hline Cesarean section & 8 & $11.1 \%$ & 13 & $18.6 \%$ & & \\
\hline Twins & 2 & $2.8 \%$ & 0 & $0 \%$ & & \\
\hline
\end{tabular}

* Independent Student's $t$ test

Table 2. Sandvik Incontinence Severity Index at baseline and after 3 months

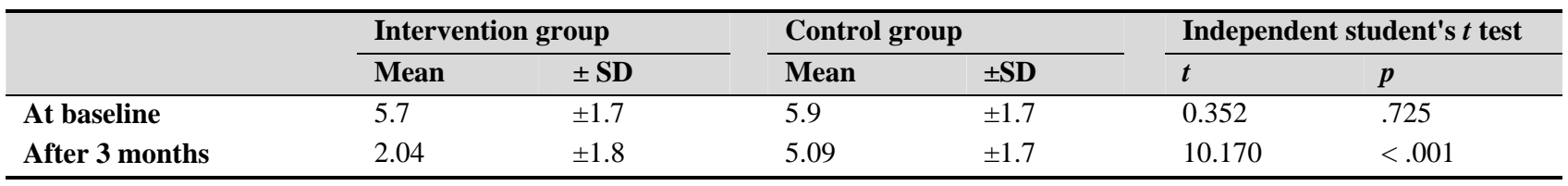

-Intervention group -Control group

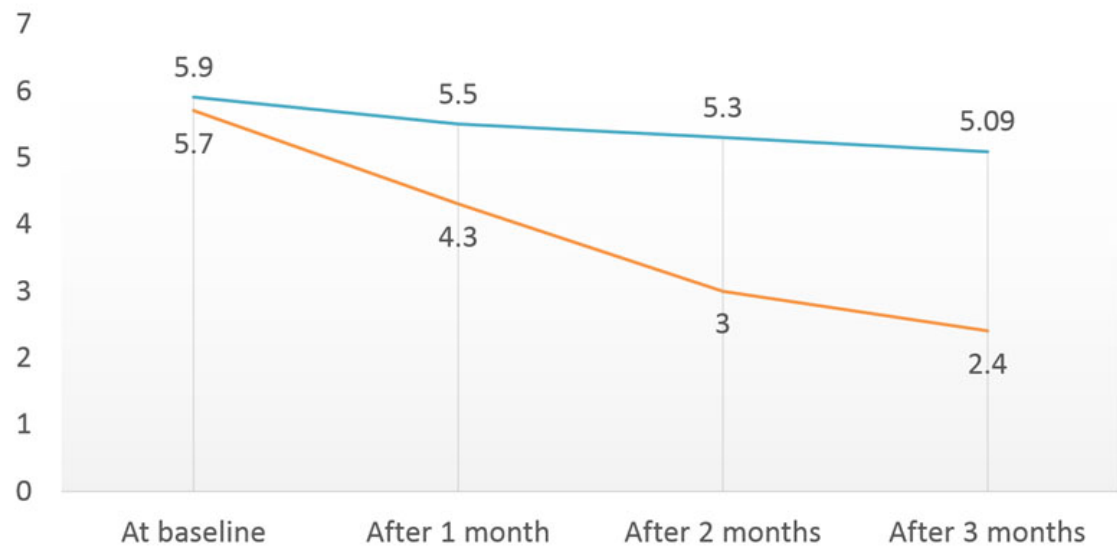

Figure 1. Change in the Sandvik Incontinence Severity Index over the treatment period in the intervention and control groups 


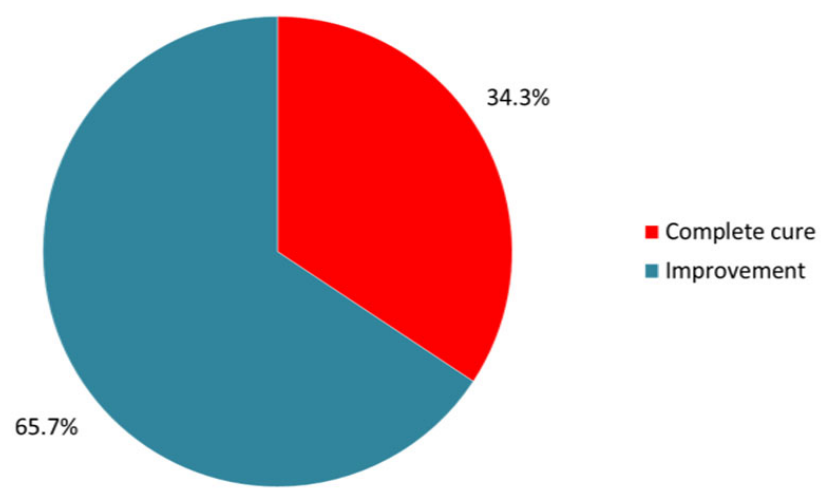

Figure 2. The complete cure rate and improvement rate after 3 months in the intervention group

\subsection{Effect of PFME on provocation test and vaginal dig- ital test}

As shown in Table 3, despite that the two groups were similar at baseline, the women in the intervention group had a significantly higher vaginal digital test score than the women in the control group ( $2.2 \pm 0.9$ versus $1.8 \pm 0.7, p=.002)$. Also, the women in the intervention group had a significantly lower provocative test score than women in the control group after three months $(0.5 \pm 0.6$ versus $0.8 \pm 0.7$ respectively, $p=$ $.006)$.

Table 3. Mean and standard deviation of the vaginal digital test and provocation test in the two groups at baseline and after 3 months

\begin{tabular}{|c|c|c|c|c|}
\hline & \multirow{2}{*}{$\begin{array}{l}\text { Intervention group } \\
\text { Mean } \pm \text { SD }\end{array}$} & \multirow{2}{*}{$\begin{array}{l}\text { Control group } \\
\text { Mean } \pm \text { SD }\end{array}$} & \multicolumn{2}{|c|}{ Independent student's $t$ test } \\
\hline & & & $t$ & $p$ \\
\hline \multicolumn{5}{|l|}{ At baseline } \\
\hline Vaginal digital test & $1.2 \pm 0.4$ & $1.3 \pm 0.5$ & 0.972 & .333 \\
\hline Provocative test & $1.1 \pm 0.7$ & $1.0 \pm 0.7$ & 0.608 & .544 \\
\hline \multicolumn{5}{|l|}{ After 3 months } \\
\hline Vaginal digital test & $2.2 \pm 0.9$ & $1.8 \pm 0.7$ & 3.232 & .002 \\
\hline Provocative test & $0.5 \pm 0.6$ & $0.8 \pm 0.7$ & 2.772 & .006 \\
\hline
\end{tabular}

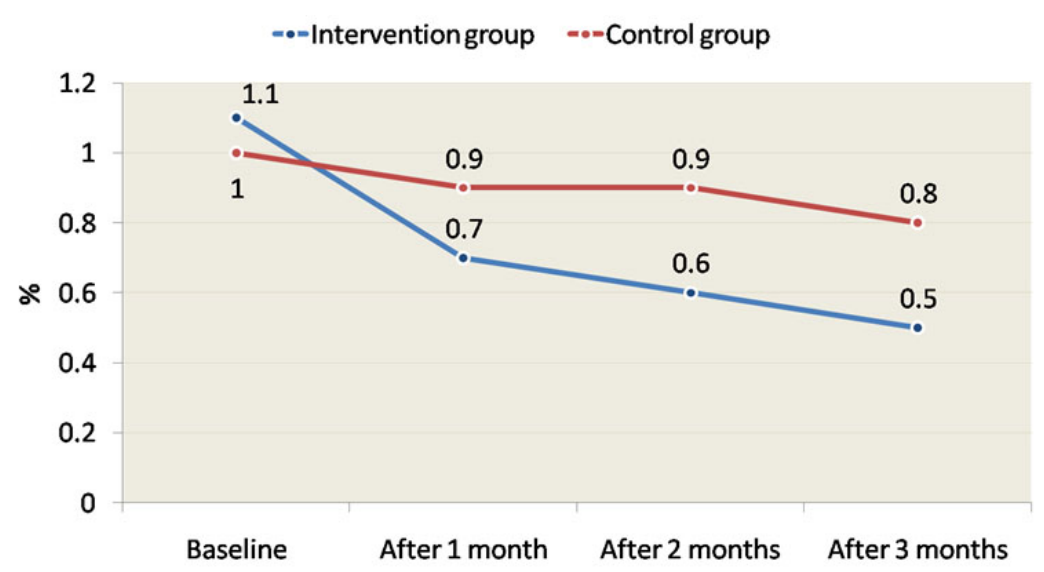

Figure 3. The change of the provocation test over the follow up period in the intervention and control groups. 


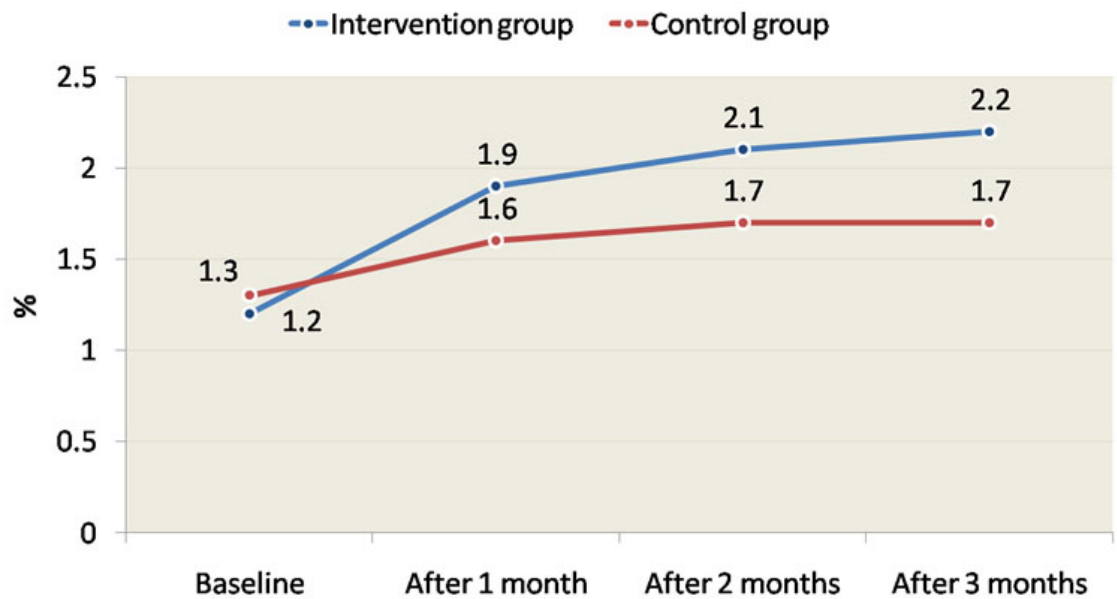

Figure 4. The change of the vaginal digital test over the follow up period in the intervention and control groups

Table 4. Number, percentage distribution and mean scores of the study groups according to the Impact of Incontinence on The Quality of Life "Short Form (IIQ-7)" after 3 months

\begin{tabular}{|c|c|c|c|c|c|c|}
\hline & \multicolumn{2}{|c|}{ Intervention group } & \multicolumn{2}{|c|}{ Control group } & \multicolumn{2}{|c|}{ Chi square test } \\
\hline & $\mathbf{N}$ & $\%$ & $\mathbf{N}$ & $\%$ & $\chi^{2}$ & $p$ \\
\hline \multicolumn{7}{|c|}{ 1. Ability to do household chores (cooking, housecleaning, laundry)? } \\
\hline Not at all & 66 & $94.3 \%$ & 6 & $8.6 \%$ & 112.867 & \multirow{4}{*}{$<.001$} \\
\hline Slightly & 4 & $5.7 \%$ & 9 & $12.6 \%$ & & \\
\hline Moderately & 0 & $0 \%$ & 35 & $50 \%$ & & \\
\hline Greatly & 0 & $0 \%$ & 26 & $37.1 \%$ & & \\
\hline \multicolumn{7}{|c|}{ 2. Physical recreation such as walking, swimming, or other exercise? } \\
\hline Not at all & 65 & $92.9 \%$ & 0 & $0 \%$ & 121.553 & \multirow{4}{*}{$<.001$} \\
\hline Slightly & 3 & $4.3 \%$ & 39 & $55.7 \%$ & & \\
\hline Moderately & 2 & $2.9 \%$ & 21 & $30 \%$ & & \\
\hline Greatly & 0 & $0 \%$ & 10 & $14.3 \%$ & & \\
\hline \multicolumn{7}{|c|}{ 3. Entertainment activities (movies, concerts, etc.)? } \\
\hline Not at all & 66 & $94.3 \%$ & 5 & $7.1 \%$ & 106.669 & \multirow{4}{*}{$<.001$} \\
\hline Slightly & 2 & $2.9 \%$ & 41 & $58.6 \%$ & & \\
\hline Moderately & 2 & $2.9 \%$ & 16 & $22.9 \%$ & & \\
\hline Greatly & 0 & $0 \%$ & 8 & $11.4 \%$ & & \\
\hline \multicolumn{7}{|c|}{ 4. Ability to travel by car or bus more than 30 minutes from home? } \\
\hline Not at all & 66 & $94.3 \%$ & 3 & $4.3 \%$ & 113.833 & \multirow{4}{*}{$<.001$} \\
\hline Slightly & 3 & $4.3 \%$ & 27 & $38.6 \%$ & & \\
\hline Moderately & 1 & $1.4 \%$ & 35 & $50 \%$ & & \\
\hline Greatly & 0 & $0 \%$ & 5 & $7.1 \%$ & & \\
\hline \multicolumn{7}{|c|}{ 5. Participation in social activities outside your home? } \\
\hline Not at all & 65 & $92.9 \%$ & 3 & $4.3 \%$ & 110.516 & \multirow{4}{*}{$<.001$} \\
\hline Slightly & 2 & $2.9 \%$ & 48 & $68.6 \%$ & & \\
\hline Moderately & 2 & $2.9 \%$ & 14 & 20 & & \\
\hline Greatly & 1 & $1.4 \%$ & 5 & $7.1 \%$ & & \\
\hline \multicolumn{7}{|c|}{ 6. Emotional health (nervousness, depression, etc.)? } \\
\hline Not at all & 67 & $95.7 \%$ & 0 & $0 \%$ & 129.125 & \multirow{4}{*}{$<.001$} \\
\hline Slightly & 3 & $4.3 \%$ & 29 & $41.4 \%$ & & \\
\hline Moderately & 0 & $0 \%$ & 37 & $52.9 \%$ & & \\
\hline Greatly & 0 & $0 \%$ & 4 & $5.7 \%$ & & \\
\hline \multicolumn{7}{|c|}{ 7. Feeling frustrated? } \\
\hline Not at all & 69 & $98.6 \%$ & 0 & $0 \%$ & 136.118 & \multirow{4}{*}{$<.001$} \\
\hline Slightly & 1 & $1.4 \%$ & 33 & $47.1 \%$ & & \\
\hline Moderately & 0 & $0 \%$ & 29 & $41.4 \%$ & & \\
\hline Greatly & 0 & $0 \%$ & 8 & $11.4 \%$ & & \\
\hline Total IIQ-7 score & 0.20 & \pm 0.97 & $55.3 \pm$ & 12.7 & 36.1938 & $<.001$ \\
\hline
\end{tabular}




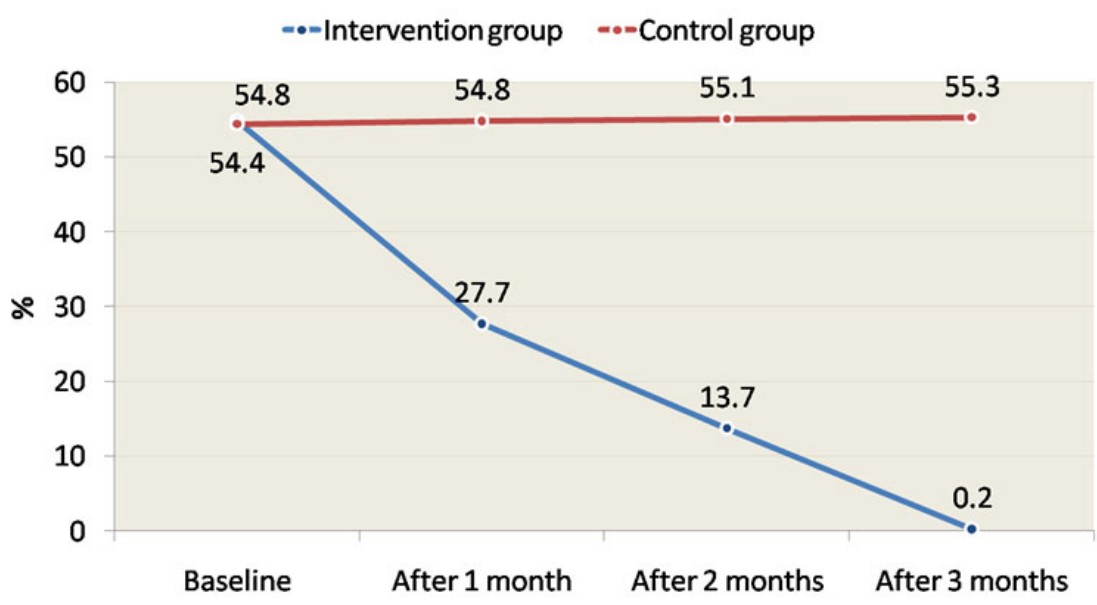

Figure 5. The change of the total over the follow up period in the intervention and control groups

\section{DiscuSsion}

Pelvic floor muscle training program is done through the patient's awareness and selective repetition of contraction and relaxation of PFM, trying to strengthen PFM tonus and tolerance, and recover the weak PFM ability in UI. At present there is insufficient evidence to determine whether PFMT is effective or ineffective at treating UI in women. ${ }^{[33]}$

The main finding of this study is that despite the equal Sandvik ISI in the two groups at baseline, the Sandvik ISI was significantly lower in the group of women who performed PFME (intervention group) than the women in the control group. Our results also revealed that after 3 months $34.3 \%$ of women in the intervention group had become continent (scored 0 in the Sandvik ISI) and the Sandvik ISI is improved in $65.7 \%$ of the women in this group compared to the baseline score.

These findings were supported by Hay-Smith and Dumoulin $^{[34,35]}$ who reported significant improvement of incontinence with PFME program. The current study results were also in line with Luginbuehl and co-workers ${ }^{[36]}$ who studied the association between PFMT and urine leak. They found that vigorous PFMT and strengthening influence female continence positively. The current study results were also in agreement with Sampselle et al. ${ }^{[37]}$ and Sangeetha and $\mathrm{Rao}^{[38]}$ who reported that PFME was found to have a significant impact on reducing leakage index score.

Also the present study findings were supported by a metaanalysis of 10 RCTs demonstrated that PFMT produced continence more often than placebo, and a meta-analysis of 6 RCTs found that PFMT improved incontinence symptoms. PFMT regimens ranged in duration from 8 weeks to 6 months, including unsupervised treatment ( 8 to 12 repetitions, 3 to 10 times a day) and supervised treatment (as long as an hour, as often as 3 times a week). Both unsupervised and supervised PFMT produced similar results. ${ }^{[39]}$

In agreement with the findings of Price et al..$^{[40]}$ and Dumoulin and Hay-Smith, ${ }^{[35]}$ the current study results revealed that after 3 months $34.3 \%$ of women in the intervention group had become continent. In this context, Pires ${ }^{[41]}$ and Burgio et al. ${ }^{[42]}$ reported significant cure rates, and reduction of incontinence episodes in patients who received behavioral interventions. Rett ${ }^{[43]}$ showed that participants who become continent represented $46.2 \%$ of the enrolled patients. Prudencio et al. ${ }^{[44]}$ found that the urinary continence appeared in $43.7 \%$ of the cases. Seidel ${ }^{[45]}$ reported that a proximately $80 \%$ of incontinent patients can be cured or improved.

From the researcher point of view, this higher cure rate, than the rate of the current study, can be explained by the treatment of associated factors, and higher number of sessions over six months intervention in the study of Prudencio and co-workers ${ }^{[44]}$ compared to 3 months intervention program in this study. Krüger et al. ${ }^{[46]}$ observed that the amount of continent patients reached $60 \%$ after PFME therapy. This difference between our findings and the findings of Krüger and colleagues may be account for by the cultural difference and educational level of the women.

The current study results revealed also that there was a statistically significant difference between the intervention and control groups in both the vaginal digital test and provocation test at the end of 3 months (see Figure $3 \& 4$ ). In this regard, FitzGerald et al. ${ }^{[47]}$ reported that vaginal digital test and provocation tests are valuable in measuring PFM strength, and in evaluating the effectiveness of the nursing interventions in clinical settings. Also these results were in agreement with one of the Cochrane reviews conducted by Dumoulin et al. ${ }^{[48]}$ done on fourteen trials involving 836 women (435 PFMT, 401 controls) that provides support 
for the widespread recommendation that PFMT be included in first-line conservative management programs for women with incontinence. Sharaf et al. ${ }^{[26]}$ reported that PFME had resulted in significant improvement in the tone of these muscles in $38.8 \%$ of the patients who performed the exercise regimen. However, the present study findings were in disagreement with Wang and Ying ${ }^{[49]}$ who reported a lack of statistically significant difference in PFM strength measured by vaginal digital test and provocative test, for management of UI after PFMT. He reported that, PFMT in the short-term cannot significantly improve the PFM tonus for UI patients.

The study findings of Flecher ${ }^{[50]}$ and Gray and David ${ }^{[51]}$ were in concurrence with the present finding as they mentioned that performing Kegel exercises regularly for 4-6 weeks helps to improve urethral resistance through active contraction of the pubococcygeus muscle which exerts a closing force on the urethra and overtime improves muscle support to the pelvic structures and strengthens the voluntary pen-urethral and pelvic musculature. Moreover, strengthening the PFM helps to support the bladder, decreases frequency and urgency of urination.

The results of the current study highlight a highly statistically significant difference in the post test in favor of the intervention group as regards QOL. Also it reveals that there is a highly statistically significant difference between the intervention and control group regarding the degree of interference of leaking urine with women's everyday life. These results are supported by Fitz et al. ${ }^{[52]}$ who found a significant decrease in the mean scores of the domains of QOL regarding the perception of health, impact of the incontinence, limitations of daily activities, physical limitations, social limitations, personal relationships, emotions and sleep.

These results are in line with study findings of Fultz and Herzog ${ }^{[53]}$ who demonstrated that, the emotional impact on the sufferers of UI is extremely important. It affects their overall QOL, placing limitations on their social activity, the way they dress, the distance they are willing to travel and several other factors of day-to-day life that continent women would not worry about.

Also the present findings are in agreement with previous studies of Oh et al. ${ }^{[54]}$ Rivalta et al. ${ }^{[55]}$ Kashanian et al. ${ }^{[56]}$ Fitz et al. ${ }^{[52]}$ who reported a significant improvement in the score of QOL in patients who become continent. One RCT evaluating QOL measures conducted by Stearman et al. ${ }^{[39]}$ found that PFMT improved activity and reduced psychological impact. Perera et al. ${ }^{[57]}$ added that the impact of SUI on the QOL may be used to guide the effectiveness of treatment.

\section{Conclusion}

In the light of the present study results, it can be concluded that; overall, the findings of the present study adds to the scientific evidence in regard to the effectiveness of PFMT program in treating UI and improving the woman's quality of life.

\section{Recommendation}

The study recommended providing a guideline to develop clinical teaching and in-service education programs for all maternity nurses and nurse educators regarding the urinary incontinence and pelvic floor muscle exercises as a preventive as well as treatment modality for urinary incontinence. Furthermore, community awareness about the positive effect of practicing pelvic floor muscle exercises among incontinent women is recommended.

\section{ACKNOWLEDGements}

Thanks go to all staff members in Talkha Maternal and Child Health Center, who expressed an interest in the work and provided every help we needed throughout this work.

\section{CONFlicts OF INTEREST Disclosure}

The author declares that there is no conflict of interest statement.

\section{REFERENCES}

[1] Milsom I. Lower urinary tract symptoms in women. Current Opinion in Urology. 2009; 19: 337-341. PMid:19444118 http://dx.doi.o rg/10.1097/MOU. Ob013e32832b659d

[2] Beji NK, Ozbas A, Aslan E, et al. Overview of the social impact of urinary incontinence with a focus on Turkish women. Urologic Nursing. 2010; 30(6): 327-34, 335. PMid:21261192

[3] Abrams P, Cardozo L, Khoury S, et al. Epidemiology. Chap 1, in: Incontinence. Paul Abrams et al. (eds). Health Publication Ltd 2009.

[4] Abrams P, Cardozo L, Fall M, et al. The tandardization of terminology of lower urinary tract function: report from the Standardisation Sub-committee of the International Continence Society. Am J Obstet Gynecol. 2002; 187: 116. http://dx.doi.org/10.1067/mob.2 002.125704
[5] Milne JL. Behavioral therapies at the primary care level: the current state of knowledge. J Wound Ostomy Continence Nurs. 2004; 31(6): 367-76, 377-8. PMid:15867712 http://dx.doi.org/10.1097/0 0152192-200411000-00008

[6] Bø K, Kvarstein B, Nygaard I. Lower urinary tract symptoms and pelvic floor muscle exercise adherence after 15 years. Obstet Gynecol. 2005; 105(5 Pt 1): 999-1005. PMid:15863536 http: //dx.doi.org/10.1097/01.A0G.0000157207.95680.6d

[7] Magon N, Kalra B, Malik S, et al. Stress urinary incontinence: What, when, why, and then what? J Midlife Health. 2011; 2(2): 57-64. PMid:22408333

[8] Hains G, Hains F, Descarreaux M, et al. Urinary incontinence in women treated by ischemic compression over the bladder area: a pilot study. J Chiropr Med. 2007; 6(4): 132-40. PMid:19674707 
http://dx.doi.org/10.1016/j.jcme.2007.10.001

[9] Contreras O. Stress urinary incontinence in the gynecological practice. Int J Gynaecol Obstet. 2004; 86 Suppl 1: S6-16. PMid:15302563 http://dx.doi.org/10.1016/j.ijgo.2004.05.004

[10] Imamura M, Abrams P, Bain C, et al. Systematic review and economic modeling of the effectiveness and cost-effectiveness of nonsurgical treatments for women with stress urinary incontinence. Health Technol Assess. 2010; 14(40): 1-188. PMid:20738930 http://dx.doi.org/10.3310/hta14400

[11] El-Azab AS, Shaaban O. Measuring the barriers against seeking consultation for urinary incontinence among Middle Eastern women. BMC Women's Health. 2010; 27(10): 3. PMid:20105307 http: //dx.doi.org/10.1186/1472-6874-10-3

[12] Edward J. Pathophysiology of stress urinary incontinence. Rev Urol. 2004; 6(suppl 5): S11-S17.

[13] Campeau L. Urodynamics in stress incontinence: when are they necessary and how do we use them? Urol Clin North Am. 2014; 41(3): 393-8. PMid:25063595 http://dx.doi.org/10.1016/j.ucl. 2 014.05 .001

[14] Kamel DM, Thabet AA, Tantawy SA, et al. Effect of abdominal versus pelvic floor muscle exercises in obese Egyptian women with mild stress urinary incontinence. Hong Kong Physiotherapy Journal. 2013; 31(1): 12-18. http://dx.doi.org/10.1016/j.hkpj. 20 12.11 .002

[15] Broome BA. The impact of urinary incontinence on self-efficacy and quality of life. Health Qual Life Outcomes. 2003; 22(1): 35. PMid:12969511 http://dx.doi.org/10.1186/1477-752 5-1-35

[16] Coyne KS, Payne C, Bhattacharyya SK, et al. The impact of urinary urgency and frequency on health-related quality of life in overactive bladder: results from a national community survey. Value Health. 2004; 7: 455. PMid:15449637 http://dx.doi.org/10.1111/j $.1524-4733.2004 .74008$. $x$

[17] Sand PK, Goldberg RP, Dmochowski RR, et al. The impact of the overactive bladder syndrome on sexual function: a preliminary report from the Multicenter Assessment of Transdermal Therapy in Overactive Bladder with Oxybutynin trial. Am J Obstet Gynecol. 2006; 195: 1730. PMid:17132474 http://dx.doi.org/10.1016/j.a jog. 2006.08 .013

[18] Hung HC, Hsiao SM, Chih SY, et al. An alternative intervention for urinary incontinence: Retraining diaphragmatic, deep abdominal and pelvic floor muscle coordinated function. Manual Therapy. 2010; 15(3): 273-279. PMid:20185357 http://dx.doi.org/10.1016 /j.math.2010.01.008

[19] Sharaf AY, El-Sebai NA, Ewieda SM, et al. The Impact of Nursing Interventions on the Control of Urinary Incontinence among Women. Journal of American Science. 2010; 6(10): 1256-1271.

[20] Deng DY. Urinary incontinence in women. Med Clin North Am. 2011; 95(1): 101-109. PMid:21095414 http://dx.doi.org/10. 1016/j.mcna.2010.08.022

[21] Rogers RG. What's best in the treatment of stress urinary incontinence? N Engl J Med. 2010; 362(22): 2124-5. PMid:20479458 http://dx.doi.org/10.1056/NEJMe1005367

[22] Giarenis I, Cardozo L. Managing urinary incontinence: what works? Climacteric. 2014; 6: 1-8.

[23] O'Donnell M, Hunskaar S. Preferences for involvement in treatment decision-making generally and in hormone replacement and urinary incontinence treatment decision-making specifically. Patient Educ Couns. 2007; 68(3): 243-51. PMid:17904327 http: //dx.doi.org/10.1016/j.pec.2007.06.009
[24] Jackson SL, Fihn SD. Exogenous estrogen and urinary incontinence. J Urol. 2009; 181(5): 1989-91. PMid:19286197 http://dx.doi .o $\mathrm{rg} / 10.1016 / \mathrm{j} \cdot$ juro.2009.02.047

[25] Wing RR, Creasman JM, West DS, et al. Program to Reduce Incontinence by Diet and Exercise. Improving urinary incontinence in overweight and obese women through modest weight loss. Obstet Gynecol. 2010; 116(2 Pt 1): 284-92. PMid:20664387 http: //dx.doi.org/10.1097/AOG.0b013e3181e8fb60

[26] Phelan S, Kanaya AM, Subak LL, et al. Weight loss prevents urinary incontinence in women with type 2 diabetes: results from the Look AHEAD trial. J Urol. 2012 Mar; 187(3): 939-44. PMid:22264468 http://dx.doi.org/10.1016/j.juro.2011.10.139

[27] Burgio KL. Update on behavioral and physical therapies for incontinence and overactive bladder: the role of pelvic floor muscle training. Curr Urol Rep. 2013; 14(5): 457-64. PMid:23913199 http://dx.doi.org/10.1007/s11934-013-0358-1

[28] Sandvik H, Hunskaar S, Seim A, et al. Validation of a severity index in female urinary incontinence and its implementation in an epidemiological survey. J Epidemiol Community Health. 1993; 47(6): 497-9. http://dx.doi.org/10.1136/jech.47.6.497

[29] Brink CA, Wells TJ, Sampselle CM, et al. A digital test for pelvic muscle strength in women with urinary incontinence. Nurs Res. 1994; 43(6): 352-6. http://dx.doi.org/10.1097/00006199-19941 1000-00006

[30] Hahn I, Milson I, Fall M, et al. Long term results of pelvic floor training in female stress incontinence. Br J Urol. 1993; 72: 421-7. http: //dx.doi.org/10.1111/j.1464-410X.1993.tb16170.x

[31] Uebersax JS, Wyman JF, Shumaker SA, et al. Short forms to assess life quality and symptom distress for urinary incontinence in women: the Incontinence Impact Questionnaire and the Urogenital Distress Inventory. Continence Program for Women Research Group. Neurourol Urodyn. 1995; 14(2): 131-9. PMid:7780440 http://dx.doi.org/10.1002/nau.1930140206

[32] Choi EP, Lam CL, Chin WY. Validation of the International Prostate Symptom Score in Chinese males and females with lower urinary tract symptoms. Health Qual Life Outcomes. 2014; 2(12): 1. PMid:24382363 http://dx.doi.org/10.1186/147 7-7525-12-1

[33] Ghodsbin F, Kargar M, Jahanbin I. The Efficiency of a Behavioral Intervention Program for Urinary Incontinence in Elderly Females. J Nurs Care. 2012; 1: 122. http://dx.doi.org/10.4172/2167-1 168.1000122

[34] Hay-Smith EJ, Dumoulin C. Pelvic floor muscle training versus no treatment, or inactive control treatments, for urinary incontinence in women. Cochrane Database Syst Rev. 2006; 1(1): CD005654. PMid:16437536

[35] Dumoulin C, Hay-Smith J. Pelvic floor muscle training versus no treatment, or inactive control treatments, for urinary incontinence in women. Cochrane Database Syst Rev. 2010; 1(1): CD005654. PMid:20091581

[36] Luginbuehl H, Baeyens JP, Taeymans J, et al. Pelvic floor muscle activation and strength components influencing female urinary continence and stress incontinence: a systematic review. Neurourol Urodyn. 2014; 18(2): 77-85.

[37] Sampselle C, Palmer M, Boyington A, et al. Prevention of urinary incontinence in adults: Population-based strategies. Nursing Research. 2004; 53(6, Suppl.): S61-S67.

[38] Sangeetha JM, Rao S. The efficacy of a comprehensive pelvic floor muscle rehabilitation program of stress urinary incontinence in women. The Indian Journal of Occupational Therapy. 2010; 42(1): 1-6. 
[39] Stearman H, Benko R, St Anna L. Clinical inquiry: How can we effectively treat stress urinary incontinence without drugs or surgery? J Fam Pract. 2014; 63(4): 213-4. PMid:24905125

[40] Price N, Dawood R, Jackson SR. Pelvic floor exercise for urinary incontinence: a systematic literature review. Maturitas. 2010; 67(4): 309-15. PMid:20828949 http://dx.doi.org/10.1016/j.mat uritas.2010.08.004

[41] Pires M. Bladder elimination and continence. In: Hoeman S. Rehabilitation nursing process, applications, outcomes. 3rd ed. St.Louis: Mosby. 2002.

[42] Burgio KL. Influence of behavior modification on overactive bladder Urology. 2002 Nov; 60(5 Suppl 1): 72-7. http://dx.doi.org/1 $0.1016 / \mathrm{S} 0090-4295(02) 01800-9$

[43] Rett MT. Quality of life in women after treatment of stress urinary incontinence with physiotherapy. Rev Bras Ginecol Obstet. 2007; 7: 110-116.

[44] Prudencio CB, Nava GT, Cardoso MA, et al. Evolution of female urinary continence after physical therapy and associated factors. Int Arch Med. 2014; 12(7): 24. PMid:24839462 http://dx.doi .org /10.1186/1755-7682-7-24

[45] Seidel S. The pursuit of urological nursing quality. International Journal of Urological Nursing. 2007; 1(1): 4-5. http://dx.doi.org /10.1111/j.1749-771X.2007.00007_4.x

[46] Krüger AP, Luz SCT, Virtuoso JF. Home exercises for pelvic floor in continent women one year after physical therapy treatment for urinary incontinence: an observational study. Rev Bras Fisioter. 2011; 7(5): 351-356. http://dx.doi.org/10.1590/S1413-3555201 1005000006

[47] FitzGerald MP, Burgio KL, Borello-France DF, et al. Pelvic-floor strength in women with incontinence as assessed by the brink scale. Phys Ther. 2007; 87(10): 1316-24. PMid:17684087 http: //dx.doi.org/10.2522/ptj.20060073

[48] Dumoulin C, Glazener C, Jenkinson D. Determining the optimal pelvic floor muscle training regimen for women with stress urinary incontinence. Neurourol Urodyn. 2011; 30(5): 746-53. PMid:21661024 http://dx.doi.org/10.1002/nau. 21104

[49] Wang LI, Ying LI. Effect of pelvic floor muscle training on the pelvic floor muscle tonus. Journal of Chinese Clinical Medicine. 2009; 4(8): 435-438.
[50] Flecher E. Differential diagnosis of high tone and low tone pelvic floor muscle dysfunction. Journal of wound, ostomy, and continence Nursing. 2005; 32(3): 10-11. http://dx.doi.org/10.1097/001 52192-200505001-00003

[51] Gray M, David D. Does biofeedback improve the efficacy of pelvic floor muscle rehabilitation for urinary incontinence or overactive bladder dysfunction in women? Journal of wound, ostomy, and continence Nursing. 2005; 32(4): 222 -5. http://dx. doi .org/10.10 97/00152192-200507000-00005

[52] Fitz FF, Costa TF, Yamamoto DM, et al. Impact of pelvic floor muscle training on the quality of life in women with urinary incontinence. Rev Assoc Med Bras. 2012; 58(2): 155-159. http: //dx.doi.org/10.1016/S0104-4230(12)70175-6

[53] Fultz NH, Herzog AR. Self-reported social and emotional impact of Urinary Incontinence. J Am Geriatr Soc. 2001; 49: 892-899. PMid: 11527480

[54] Oh HS, Kim MK, Seo WS. Effectiveness of a behavioral intervention program for urinary incontinence in a community setting. Taehan Kanho Hakhoe Chi. 2005; 35(8): 1476-1484. PMid:16415628

[55] Rivalta M, Sighinolfi MC, Micali S, et al. Sexual function and quality of life in women with urinary incontinence treated by a complete pelvic floor rehabilitation program (biofeedback, functional electrical stimulation, pelvic floor muscles exercises, and vaginal cones). $\mathrm{J}$ sex Med. 2010; 7(3): 1200-1208. http://dx.doi.org/10.1111/j.1 743-6109.2009.01676.x

[56] Kashanian M, Ali SS, Nazemi M, et al. Evaluation of the effect of pelvic floor muscle training (PFMT or Kegel exercise) and assisted pelvic floor muscle training (APFMT) by a resistance device (Kegelmaster device) on the urinary incontinence in women: a randomized trial. Eur J Obstet Gynecol Reprod Biol. 2011; 159(1): 218-223. PMid:21741151 http://dx.doi.org/10.1016/j.ejo grb.2011.06.037

[57] Perera J, Kirthinanda DS, Wijeratne S, et al. Descriptive cross sectional study on prevalence, perceptions, predisposing factors and health seeking behaviour of women with stress urinary incontinence. BMC Womens Health. 2014; 2(14): 78. PMid:24985068 http://dx.doi.org/10.1186/1472-6874-14-78 